\title{
Penerapan Model Pembelajaran Predict ObSERVE Explain Write (POEW) TERHADAP PEMAHAMAN KONSEP SISWA Pada MATERi Kalor dan PERPINDAhanNya
}

\author{
Shirajuddin $^{1}$, Eka Murdani ${ }^{2}$, Intan Kusumawati ${ }^{3}$ \\ STKIP Singkawang, Singkawang, Indonesia \\ shirajuddin5995@gmail.com ${ }^{1}$, ekamurdani@gmail.com, ${ }^{2}$ intankusumawati99@gmail.com
}

Keywords :

POEW, Pemahaman Konsep,

Kalor dan Perpindahannya

\begin{abstract}
Rendahnya pemahaman konsep siswa diduga ada hubungannya dengan proses pembelajaran yang terjadi pada saat pembelajaran fisika. Penelitian ini bertujuan untuk mendapatkan gambaran peningkatan pemahaman konsep siswa setelah diterapkan model pembelajaran POEW pada materi kalor dan perpindahannya. Jenis penelitian ini adalah penelitian pre eksperimental design dengan rancangan one-group pre test-post test design. Populasi dalam penelitian ini adalah siswa kelas X di SMA Negeri 5 Singkawang. Sampel penelitian ini adalah siswa kelas XA dengan teknik pengambilan sampel menggunakan purposive sampling. Peningkatan pemahaman konsep siswa diukur dengan menggunakan alat ukur tes yang berjumlah 14 soal pilihan ganda yang sebelumnya telah validasi. Dari hasil analisis $N$-gain, diperoleh peningkatan pemahaman konsep sebesar 0,62 dengan kriteria sedang. simpulan penerapan model pembelajaran POEW dapat meningkatkan pemahaman konsep siswa pada materi kalor dengan kategori peningkatannya yang sedang.
\end{abstract}

\section{PENDAHULUAN}

Perkembangan ilmu pengetahuan yang sangat cepat mengakibatkan pembelajaran Ilmu Pengetahuan Alam atau Sains tidak cukup jika hanya bertujuan membekali materi sebanyak-banyaknya terhadap siswa. Kemajuan ilmu pengetahuan dan kompleksnya tingkat berpikir siswa, menuntut guru atau pendidik untuk menciptakan pembelajaran yang inovatif (Permatasari, 2017: 50).

Ilmu Pengetahuan Alam (IPA) berkaitan dengan cara mencari tahu tentang fenomena alam secara sistematis, sehingga IPA bukan hanya penguasaan kumpulan pengetahuan yang berupa fakta-fakta, konsep-konsep, atau prinsip-prinsip (Permendiknas, 2006: 433). IPA adalah pengetahuan tentang dunia alamiah yang meliputi tiga bidang ilmu dasar, yaitu Biologi, Fisika, dan Kimia. (Sari, dkk, 2012: 145). Pada hakikatnya IPA dibangun atas dasar produk ilmiah, proses ilmiah, dan sikap ilmiah (Trianto, 2010: 137). Jadi IPA tidak hanya terdiri atas kumpulan pengetahuan atau fakta yang dihafal, namun IPA merupakan kegiatan atau proses yang aktif menggunakan pikiran dalam mempelajari rahasia gejala alam. 
Satu diantara cabang Ilmu Pengetahuan Alam (IPA) adalah Fisika. Fisika merupakan ilmu yang mempelajari gejala alam yang dibentuk oleh interaksi berbagai besaran fisis. Unsur yang terkandung dalam pembelajaran Fisika dapat bersifat makroskopis (dapat dilihat secara kasat mata), maupun mikroskopis (tidak kasat mata) (Kusumawati, 2015). Proses pembelajaran Fisika tidak hanya ditekankan pada pengetahuan fakta-fakta, penghafalan rumus tetapi perlu dilengkapi dengan pemahaman konsep yang mendasar. Akibatnya, perlu adanya proses penemuan secara mandiri agar pengetahuan yang diperoleh tersimpan sebagai pengetahuan yang lebih bermakna (Ulya, dkk, 2013: $18)$.

Belajar Fisika tidak akan lepas dari kehidupan sehari-hari. Pembelajaran Fisika menekankan pada proses pengetahuan yang diperoleh dapat digunakan. Tujuan pembelajaran Fisika adalah membantu siswa memperoleh pengetahuan dasar secukupnya yang dapat digunanakan secara fleksibel (Wiyanto, 2008: 11). Pembelajaran Fisika juga diarahkan untuk memperoleh kemampuan menggunakan secukupnya pengetahuan dasar yang berguna dalam menjelaskan atau memecahkan dan memahami konsep dasar (Ulya, dkk, 2013: 18).

Menurut Trianto (2007: 65) mengemukakan bahwa proses pembelajaran siswa hanya menghafal konsep sehingga kurang mampu menggunakan konsep tersebut jika menemui masalah dalam kehidupan nyata yang berhubungan dengan konsep yang dimiliki. Proses pembelajaran di dalam kelas lebih banyak diarahkan kepada siswa untuk menghafal informasi tanpa dituntut untuk memahami dan mengembangkan informasi yang diingat dalam kehidupan sehari-hari. Permasalahan tersebut dikarenakan model pembelajaran yang digunakan kurang inovatif, guru cenderung menggunakan ceramah dan tugas, serta metode yang digunakan kurang mendukung untuk proses pembelajaran Fisika, sehingga siswa tidak aktif terlibat dalam pembelajaran. Dengan demikian pembelajaran IPA khususnya Fisika yang baik seharusnya tidak hanya sekedar menghafal, melainkan lebih menekankan pada proses terbentuknya suatu pengetahuan dan penguasaan siswa terhadap konsep sehingga siswa dituntut untuk bisa memperoleh pengetahuaan dengan peran aktifnya selama kegiatan pembelajaran berlangsung (Azizah, dkk 2013: 235-236).

Pembelajaran yang terjadi di lapangan belum sesuai dengan apa yang diharapkan, hal ini tercermin dari data hasil studi pendahuluan di SMA Negeri 5 Singkawang, diperoleh skor rata-rata pemahaman konsep siswa 25 dari skor maksimal 100. Rendahnya pemahaman konsep siswa diduga ada hubungannya dengan proses pembelajaran yang terjadi, dimana berdasarkan hasil wawancara kepada guru Fisika dan siswa SMA Negeri 5 Singkawang menunjukkan bahwa pembelajaran yang biasa dilakukan lebih menekankan pada hasil akhir dan dalam proses pembelajaran berpusat pada guru. Adapun yang dilakukan guru adalah guru memberikan latihan soal, penugasan, dan guru dalam menyampaikan materi cenderung kurang. Kegiatan belajar yang memberikan pengalaman langsung pada siswa contohnya melakukan pengamatan ataupun percobaan. Siswa juga dibiasakan pada pemecahan masalah dan penugasan yang bentuk hitungan dan tentunya ini membuat siswa kesulitan dalam memahami konsep Fisika. Hal ini diperkuat oleh pendapat Kurniawan, (2012: 208) menyatakan bahwa proses pembelajaran Fisika yang memfokuskan pada rumus, hitungan saja pada akhirnya tidak melibatkan siswa dalam proses menemukan konsep. Demikian pula pada proses pembelajaran Fisika yang tanpa mengaitkan antara konsep dengan aplikasinya secara langsung, membuat siswa kurang tertarik yang membuat pemahaman konsep siswa rendah Saputra, dkk (2013: 118).

Berdasarkan hal tersebut, maka diperlukan penelitian guna meningkatkan pemahaman konsep siswa dengan inovasi proses pembelajaran. Adapun inovasi proses pembelajaran ini berupa penerapan model pembelajaran yang dapat meningkatkan pemahaman konsep siswa, menghasilkan respon positif bagi siswa (Suryani, 2014: 26). Adapun model pembelajaran yang digunakan untuk meningkatkan pemahaman konsep siswa dalam penelitian ini adalah dengan menerapkan model pembelajaran POEW. 
Model pembelajaran POEW merupakan model pembelajaran yang memungkinkan siswa dapat aktif dalam proses pembelajaran, memberikan kesempatan terhadap siswa untuk mengonstruksi pengetahuannya, mengkomunikasikan pemikirannya dan menuliskan hasil diskusinya sehingga siswa lebih memahami dan menguasai konsep yang diajarkan (Supriyati, 2013: 4). Adapun sintaks model pembelajaran POEW sebagai berikut. Predict, yaitu memprediksi atau membuat dugaan terhadap suatu permasalahan yang diberikan guru. Observe, yaitu melakukan penyelidikan atau pengamatan apa yang terjadi. Explain, yaitu memberi penjelasan tentang kesesuaian antara dugaan dengan hasil eksperimen dari tahap observasi dan Write, yaitu siswa menulis kesimpulan dengan bahasanya sendiri.

Pemahaman adalah kemampuan seseorang dalam mengartikan, menafsirkan, menerjemahkan atau menyatakan sesuatu dengan caranya sendiri tentang pengetahuan yang pernah diterimanya (Lisma, 2017: 35). Pemahaman merupakan suatu jenjang di ranah kognitif yang menunjukan kemampuan menjelaskan hubungan yang sederhana antara fakta-fakta dan konsep (Arikunto, 2007: 118). Pemahaman memerlukan kemampuan menangkap makna atau arti dari sesuatu konsep. Untuk itu maka diperlukan adanya hubungan atau pertautan antara konsep dengan makna yang ada dalam konsep tersebut. Pemahaman yang dimaksud ini adalah suatu kemampuan untuk mengerti secara benar konsep-konsep atau fakta-fakta. Pemahaman juga sebagai salah satu indikator keberhasilan belajar siswa dapat bernilai amat baik, baik, cukup, dan jelek.

Konsep merupakan ide yang mengkombinasikan beberapa unsur berbeda ke dalam satu unsur tunggal (Suprijono, 2009: 15). Setiap konsep tidak dapat berdiri sendiri, setiap konsep dapat dihubungkan dengan konsep-konsep lain dan hanya mempunyai makna bila dikaitkan dengan konsep-konsep lain. Konsep-konsep bersama-sama membentuk semacam jaringan pengetahuan di dalam kepala manusia. Pemahaman tentang sebuah konsep sangat penting dalam pembelajaran di kelas karena manfaat belajar konsep akan memberikan keuntungan bagi siswa. Keuntungan dari belajar konsep adalah:

1) mengurangi beban berat memori karena kemampuan manusia dalam mengkategorikan berbagai stimulus terbatas.

2) merupakan unsur pembangun berpikir.

3) merupakan dasar proses mental yang lebih tinggi.

4) diperlukan untuk memecahkan masalah.

Pemahaman konsep merupakan kemampuan mengungkapkan makna suatu konsep yang meliputi kemampuan membedakan, menjelaskan, menguraikan lebih lanjut, dan mengubah konsep (Salma, 2015: 18). Pemahaman konsep adalah kemampuan mengungkapkan makna suatu konsep atau faktafakta. Pemahaman sebagai satu diantara indikator kadar keberhasilan belajar siswa dapat bernilai sangat baik, baik, cukup baik, dan kurang baik. Pemahaman konsep sangat penting, karena dengan penguasan konsep akan memudahkan siswa dalam memepelajari Fisika mampu menjelaskan kembali yang telah dipelajari. Pemahaman juga menyangkut kemampuan menangkap makna dari materi pembelajaran, termasuk apa yang diucapkan, ditulis, dan digambar oleh guru. Proses kategori dalam memahami meliputi menafsirkan, mencotohkan, mengklasifikasikan, merangkum, menyimpulkan, membandingkan, dan menjelaskan (Anderson dan Krathwohl: 105-114). Dari latar belakang di atas peneliti tertarik untuk meneliti, apakah pemahaman konsep siswa meningkat setelah diterapkan model pembelajaran POEW pada materi kalor dan perpindahannya.

\section{METHOD}

Jenis penelitian ini adalah penelitian kuantitatif, dengan menggunakan metode yang digunakan adalah Pre experimental design. Desain penelitian menggunakan One Group Pre test Post test. Populasi dalam penelitian ini adalah seluruh siswa kelas X di SMA Negeri 5 Singkawang. Sampel penelitian ini adalah siswa kelas XA. Teknik pengambilan sampel dalam penelitian ini adalah purposive sampling dimana sampel diambil berdasarkan pertimbangan tertentu, yang dalam hal ini adalah saran dari guru fisika yang mengajar di SMA tersebut. 
Teknik pengumpulan data dalam penelitian ini menggunakan tes pemahaman konsep. Tes yang berbentuk soal pilihan ganda sebanyak 14 Soal sebelumnya telah di validasi. Instrumen yang digunakan adalah soal tes dengan bentuk pilihan ganda. Sebelum diujikan, instrumen telah diujicobakan untuk mengetahui tingkat kesukaran, daya pembeda dan reliabilitasnya.

Hasil tes dianalisis dengan menggunakan rumus $N$-gain sebagai berikut:

$$
\langle g\rangle=\frac{S_{\text {post-test }}-S_{\text {pre-test }}}{S_{\text {maksimum }}-S_{\text {pre-test }}}
$$

(Hake, 1999:1)

Keterangan :

$\langle g\rangle=$ Dinormalisasi dari kedua model

$S_{\text {post test }}=$ Skor tes akhir

$S_{\text {pre test }}=$ Skor tes awal

$S_{\text {maks }}=$ Skor maksimum dari tes awal dan akhir

Adapun kriteria $N$-gain yang dapat dilihat pada Tabel 3.10 sebagai berikut.

TABEL 1

Normalisasi N-Gain

\begin{tabular}{cc}
\hline$\langle g\rangle$ & Kategori \\
\hline$\langle g\rangle \geq 0,7$ & Tinggi \\
$0,3 \leq\langle g\rangle<0,7$ & Sedang \\
$\langle g\rangle<0,3$ & Rendah \\
\hline
\end{tabular}

(Hake, 1999:1)

\section{HASIL DAN PEMBAHASAN}

Dari hasil penelitian yang dilakukan diperoleh peningkatan setiap aspek pemahaman konsep dengan menggunakan $\mathrm{N}$-gain sebagai berikut:

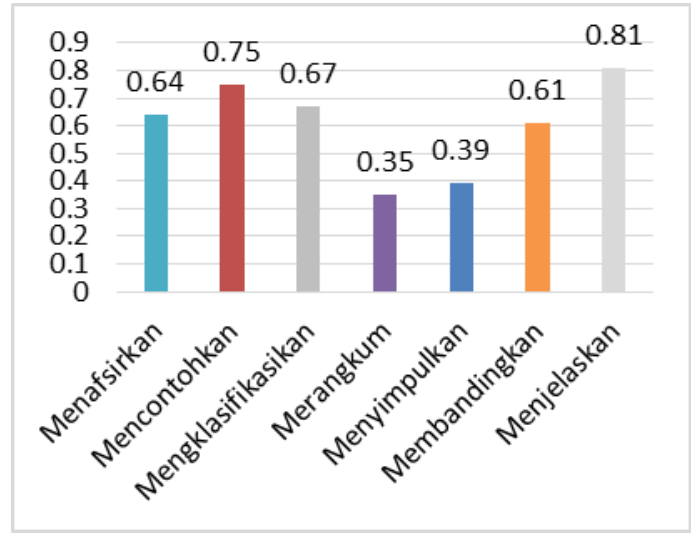

Gambar 4.2 Grafik skor N-gain setiap aspek

Berdasarkan hasil analisis data dapat dilihat bahwa pada semua aspek pemahaman konsep mengalami peningkatan setelah diterapkan model pembelajaran POEW. Dari data di atas dijelaskan bahwa aspek menafsirkan mengalami peningkatan sebesar 0,64 dengan kategori sedang. Aspek mencontohkan mengalami peningkatan sebesar 0,75 dengan kategori tinggi. Aspek mengklasifikasikan mengalami peningkatan sebesar 0,67 dengan kategori sedang. Aspek merangkum mengalami peningkatan sebesar 0,35 dengan kategori sedang. Aspek menyimpulkan mengalami peningkatan sebesar 0,39 dengan kategori sedang. Aspek membandingkan percobaan mengalami peningkatan sebesar 0,61 dengan kategori sedang. Aspek menjelaskan mengalami peningkatan sebesar 0,81 dengan kategori tinggi. Dari keseluruhan aspek yang diteliti, rata-rata peningkatan seluruh aspek yang diteliti diperoleh sebesar 0,62 dengan kategori sedang setelah diterapkan setelah 
diterapkannya model pembelajaran POEW. Hal ini membuktikan bahwa model pembelajaran POEW dapat meningkatkan pemahaman konsep siswa. Buyung, B., Nirawati, R., \& Kusumawati, I. (2016) bahwa Kurang adanya kesadaran dan keinginan dari diri siswa untuk belajar, kurangnya dorongan untuk menumbuhkan minat belajar, serta kurangnya kemampuan pemahaman konsep siswa sehingga menjadi penyebab dari rendahnya aktivitas belajar siswa tersebut. Dengan demikian setelah diterapkan model pembelajaran POEW kemampuan pemahaman konsep siswa menjadi meningkat.

Berdasarkan hasil $\mathrm{N}$-gain peningkatan pemahaman konsep dikategorikan sedang karena siswa masih belum terbiasa melakukan pembelajaran dengan model pembelajaran POEW, hal ini dapat dilihat pada lembar respon siswa sebagian besar menyatakan bahwa pembelajaran yang dialaminya berbeda dengan pembelajaran sebelumnya.

\section{KESIMPULAN DAN SARAN}

\section{KESIMPULAN}

Kesimpulannya adalah penerapan model pembelajaran POEW dapat meningkatkan pemahaman konsep siswa pada materi kalor dengan kategori peningkatannya yang sedang.

\section{SARAN}

Berdasarkan temuan-temuan selama penelitian, sebagai tindak lanjut dari penelitian diberikan beberapa saran yaitu : (1) Model pembelajaran POEW sebaiknya diterapkan pada materi fisika yang memungkinkan siswa untuk melakukan percobaan. (2) Di awal pembelajaran siswa sebaiknya diberi motivasi agar semangat dan rasa ingin tahu mereka meningkat.

\section{DAFTAR PUSTAKA}

Anderson, L. W., Krathwohl, D. R. 2010. Kerangka Landasan untuk Pembelajaran, Pengajaran dan Assessment. Jakarta: Pustaka Pelajar

Arikunto, S. 2007. "Prosedur Penelitian Suatu Pendekatan Praktik”. Jakarta: Rineka Aksara.

Azizah, N., Indrawati., Harijanto, A. 2013. "Penerapan Model Inkuiri Terbimbing Untuk Meningkatkan Keterampilan Proses IPA Dan Hasil belajar Fisika Siswa Kelas X.C Di MAN 2 Jember Tahun Ajaran 2013/2014". Jurnal Pendidikan Fisika, Vol. 3 No.3, Desember 2014, hal $235-241$.

Buyung, B., Nirawati, R., \& Kusumawati, I. (2016). Pengaruh Strategi Pembelajaran Inkuiri (SPI) Terhadap Kemampuan Pemahaman Konsep Siswa Kelas VIII SMP Negeri 18 Singkawang. JPMI (Jurnal Pendidikan Matematika Indonesia), 1(2), 87-90.

Hake, R. R. 1998. Interactive-engagement vs traditional methods: A six-thousand-student survey of mechanics test data for introductory physics courses. National Science Foundation, Arlington, VA.

Kurniawan, T, D. 2012. "Model Pembelajaran Berbasis Masalah Berbantuan Website Interaktif Pada Konsep Fluida Statis Untuk Meningkatkan Pengusaan Konsep Dan Keterampilan Proses Sains Siswa Kelas XI". Universitas Swadaya Gunung Jati Cirebon, Jurnal Pengajaran MIPA, Vol 19, No 2.

Kusumawati, I., Marwoto, P., \& Linuwih, S. (2015, September). Implementation multi representation and oral communication skills in Department of Physics Education on Elementary Physics II. In AIP Conference Proceedings (Vol. 1677, No. 1, p. 040017). AIP Publishing.

Lisma, L., Kurniawan, Y., \& Sulistri, E. (2017). Penerapan Model Learning Cycle (LC) 7E Sebagai Upaya Peningkatan Pemahaman Konsep Aspek Menafsirkan dan Menyimpulkan Materi Kalor Kelas X SMA. JIPF (Jurnal Ilmu Pendidikan Fisika), 2(2), 35-37.

Nana, 2016. "Pengembangan Model Pembelajaran Prediction Observation Explanation Elaboration Write And Evaluation ( $\mathrm{POE}_{2} \mathrm{WE}$ ) Dalam Pembelajaran Fisika SMA". (Skripsi). Universitas Sebelas Maret Surakarta. 
Permatasari, O. I., \& Marwoto, P. (2017). Penerapan Model Pembelajaran Predict-Observe-Explain Berbasis Kontekstual Untuk Meningkatkan Aktivitas dan Pemahaman Konsep Siswa SMP. JIPF (Jurnal Ilmu Pendidikan Fisika), 2(2), 50-53.

Permendiknas, No 22 Tahun 2006. Tentang Standar Isi Pendidikan Dasar dan Menengah, Jakarta.

Salma, M. V. 2015. "Pengembangan E-Daignostic Test untuk Mengidentifikasi Pemahaman Konsep Fisika Siswa SMA Pada Pokok Bahasan Kalor" (Skripsi). Universitas Negeri Semarang.

Sari, T. A., Bektiarso, S., Yushardi. 2012. "Penerapan Model Pembelajaran Generatif Dengan Metode Demonstrasi Dalam Pembelajaran Fisika di SMP". Jurnal Pembelajaran Fisika, FKIP Universitas Jember, Volume 1, Nomor 3, Desember 2012 ISSN : 2301-9794.

Saputra, D. M. E., dan Nyeneng, P. D. I., Maharta, N. 2013. "Pengaruh Kemampuan Berpikir terhadap Penguasaan Konsep Dan Hasil Belajar Siswa Dengan Pendekatan Keterampilan Proses". Pendidikan Fisika Unila.

Supriyati, 2013. "Pengembangan Model pembelajaran POEW Untuk Meningkatkan Penguasaan Konsep, Keterampilan Kritis, Dan Mendapatkan Gambaran Kuantitas Miskonsepsi Siswa SMA Pada Materi Suhu Dan Kalor" (Skripsi), Universitas Pendidikan Indonesia.

Suprijono, A. 2009. Cooperative Learning. Yogyakarta: Pustaka Pelajar

Suryani, F. 2014. "Peningkatan Prestasi Siswa pada Konsep Kalor dengan Model Pembelajaran Kooperatif Tipe Two Stay-Two Stray (TS-TS) Bervariasi Demonstrasi di Kelas XI IPA SMA Negeri 5 Yogyakarta TA 2012-2013". JRKPF UAD, Vol.1, No.1, 26-30.

Trianto. 2007. "Model-model Pembelajaran Inovatif Berorientasi Konstruktivistik". Jakarta: Prestasi Pustaka Publisher

Ulya, S., Hindarto, N., Nurbaiti, U. 2013. "Keefektifan Model Pembelajaran Guided Inquiry Berbasis Think Pair Share (TPS) Dalam Meningkatkan Pemahaman Konsep Fisika Kelas XI SMA". Unnes Physics Education Journal, Jurusan Fisika, Fakultas Matematika dan Ilmu Pengetahuan Alam Universitas Negeri Semarang, Indonesia, 50229. ISSN 2252-6935

Wiyanto. 2008. "Menyiapkan Guru IPA Mengembangkan Kompetensi Laboratorium". Semarang: UNNES PRESS. 